\title{
E6AP promotes the degradation of the PML tumor suppressor
}

\author{
I Louria-Hayon ${ }^{1,6}$, O Alsheich-Bartok ${ }^{1,6}$, Y Levav-Cohen ${ }^{1}$, I Silberman ${ }^{1}$, M Berger ${ }^{1}$, T Grossman ${ }^{1}$, K Matentzoglu², Y-H Jiang ${ }^{3}$, \\ $S$ Muller ${ }^{4}$, M Scheffner ${ }^{2}$, S Haupt ${ }^{5}$ and $Y$ Haupt $^{*, 1,5}$
}

The promyelocytic leukemia (PML) tumor suppressor is essential for the formation of PML nuclear bodies (NBs). PML and PMLNBs have been implicated in the regulation of growth inhibition, senescence and apoptosis. PML is activated in response to stress signals and is downregulated in certain human cancers. However, the factors mediating PML stability are incompletely understood. Here we demonstrate that a catalytically active form of the mammalian E3 ligase E6AP (HPV E6-associated protein) acts to reduce the half-life of the PML protein by promoting its degradation in the proteasome. E6AP mediates the ubiquitination of PML in an in vitro ubiquitination assay. E6AP and PML interact at physiological levels and colocalize in PML-NBs. Importantly, PML protein expression is elevated in multiple organs and cell types from E6AP null mice and in lymphoid cells is associated with increased number and intensity of PML-NBs. This PML elevation is enhanced in response to DNA damage. Our results identify E6AP as an important regulator of PML and PML-NBs.

Cell Death and Differentiation (2009) 16, 1156-1166; doi:10.1038/cdd.2009.31; published online 27 March 2009

The promyelocytic leukemia (PML) tumor suppressor is implicated in the regulation of cell-cycle progression, premature senescence (triggered by oncogenic Ras) and apoptosis (reviewed by Bernardi and Pandolfi ${ }^{1}$ ). Deregulation of PML can be oncogenic. PML-RAR $\alpha$ contributes to acute promyelocytic leukemia $(\mathrm{APL})^{2,3}$ and downregulation of PML was observed in multiple human cancers. ${ }^{4} \mathrm{PML}$ knockout (KO) mice are resistant to lethal doses of ionizing irradiation (IR), and exhibit genomic instability and enhanced susceptibility to tumorigenesis upon exposure to carcinogens ${ }^{1,5}$ or in the context of additional oncogenic events (e.g., a loss of Pten $^{6}$ ). The myriad of PML functions have been linked to its function in PML nuclear body (PML-NB) formation. ${ }^{7}$ These are dynamic structures whose configuration and composition are modified in response to specific stress signals. ${ }^{8}$ However, their mechanisms of action are only partially understood and are believed to be mediated by key proteins that are recruited to these structures, including pRb, SUMO, Daxx and $p 53 .{ }^{9}$ The regulation of certain proteins, such as p53, is associated with the PML-NBs. ${ }^{9}$

Stress stimuli that have been identified as activators of PML and PML-NBs include interferon ( $\alpha$ and $\gamma$ ), DNA damage, oncogenic stress and viral infection (reviewed in references $\left.{ }^{1,8,10}\right)$. In contrast, exposure of cells to arsenic trioxide $\left(\mathrm{As}_{2} \mathrm{O}_{3}\right)$ or retinoic acid promotes $\mathrm{PML}$ degradation. ${ }^{11}$ In contrast, the overexpression of specific cellular ubiquitin ligases, such as the Siah protein, ${ }^{12}$ or certain viral ubiquitin ligases, such as the ICPO regulatory protein of herpesvirus- $1,{ }^{10}$ promotes the proteasomal degradation of PML and PML-RAR $\alpha$. However, the nature of the underlying mechanism of this degradation and whether it occurs under physiological conditions is not known. Recently, a function for CK2-mediated phosphorylation of PML (on serine 517) in the control of its protein stability was demonstrated. ${ }^{13}$ In addition to phosphorylation, the covalent modification of PML by SUMO has been shown to regulate its function and stability. Three major SUMO attachment sites were identified in PML: $\mathrm{K} 65, \mathrm{~K} 160$ and K490. ${ }^{14}$ SUMOylation of PML targets it into the nuclear matrix and triggers the recruitment of NB-associated proteins, ${ }^{15,16}$ consistent with the reverse effect being mediated by the SUMO-specific protease SENP-1 (SuPr). ${ }^{17}$ The function of SUMOylation and the SUMO binding motif in the formation of the PML-NBs has recently been described. ${ }^{18}$ Treatment of cells with $\mathrm{As}_{2} \mathrm{O}_{3}$ induces SUMOylation and subsequent proteasomal degradation of PML and PML/ RAR $\alpha .{ }^{19}$ The degradation of arsenic-induced poly-SUMOylated PML is mediated by the SUMO-specific E3 ligase RNF4 (SNURF). ${ }^{20,21}$

Here we demonstrate a function for E6AP in the regulation of PML. E6AP is encoded by the UBE3A locus, which is

\footnotetext{
${ }^{1}$ Lautenberg Center for General and Tumour Immunology, The Hebrew University, Hadassah Medical School, Jerusalem 91120, Israel; ${ }^{2}$ Department of Biology, Box M642, University of Konstanz, 78457 Konstanz, Germany; ${ }^{3}$ Department of Molecular and Human Genetics, Baylor College of Medicine, Houston, Texas 77030, USA; ${ }^{4}$ Department of Molecular Cell Biology, Max Planck Institute of Biochemistry, Am Kopfershpitz 18, D-B2152 Martinsried, Germany and ${ }^{5}$ Research Division, Peter MacCallum Cancer Centre, Melbourne, Victoria 8006, Australia

${ }^{*}$ Corresponding author: Y Haupt, Lautenberg Center for General and Tumor Immunology, The Hebrew University, Hadassah Medical School, POB 12272, Jerusalem 91120, Israel. Tel: +613965 658 71; Fax: + 613965614 11; E-mail: ygal.haupt@petermac.org

${ }^{6}$ These authors contributed equally to this work.

Keywords: PML; E6AP; ubiquitination; protein degradation; DNA damage

Abbreviations: PML, promyelocytic leukemia; NBs, nuclear bodies; E6AP, E6-associated protein; APL, acute promyelocytic leukemia; KO, knockout; IR, ionizing irradiation; SNURF, SUMO-specific E3 ligase RNF4; HPV, human papillomavirus; HECT, homologous to the E6AP C terminus; BM, bone marrow; DMEM, Dulbecco's modified Eagle's medium

Received 12.2.08; revised 28.1.09; accepted 29.1.09; Edited by G Melino; published online 27.3.09
} 
mutated in Angelman syndrome, a human disorder involving motor dysfunction and mental retardation. ${ }^{22}$ E6AP was initially identified as the E3 ligase that cooperates with the human papillomavirus (HPV) E6 protein from the high-risk virus types to promote $\mathrm{p} 53$ degradation. ${ }^{23,24}$ E3 ligases confer substrate specificity for degradation through the ubiquitinproteasome system. E6AP is the prototype of the subfamily of E3 ligases that covalently bind ubiquitin and are characterized by a C-terminal HECT (homologous to the E6AP $\mathrm{C}$ terminus) domain. ${ }^{23,25}$ Here we demonstrate that E6AP promotes the proteasomal degradation of $\mathrm{PML}$ and regulates PML-NB formation.

\section{Results}

E6AP decreases PML protein levels. To evaluate the function of E6AP on PML regulation, we examined the effect of E6AP on the steady-state levels of PML. H1299 cells were transiently transfected with Flag-tagged human PML-IV (hereafter referred to as $\mathrm{PML}$ ) either alone or with increasing amounts of E6AP expression plasmids. At $48 \mathrm{~h}$ after transfection, the amount of PML protein was determined by western blot analysis. Strikingly, PML expression levels were markedly reduced in cells co-transfected with E6AP, in a dose-dependent manner (Figure 1a). This result suggests that E6AP regulates the expression levels of PML. Further, this effect of E6AP was also observed in human embryonic kidney 293 (HEK293) cells (data not shown). Because E6AP is an E3 ubiquitin ligase, the contribution of its catalytic activity to this effect was questioned. For this purpose, the effect of a catalytically inactive E6AP mutant (E6AP-C833A), which behaves as a dominant-negative mutant, ${ }^{24}$ on $\mathrm{PML}$ levels was evaluated. By marked contrast to wt E6AP, E6APC833A mutant promoted the accumulation of PML in a dosedependent manner (Figure 1b). Because PML is expressed as multiple isoforms we asked whether other isoforms of $\mathrm{PML}^{26}$ are also regulated by E6AP. As shown in Figure 1c, isoforms I, II, III, V and VI are also degraded by wt E6AP and are stabilized by E6AP-C833A mutant. These results strongly implicate E6AP in the degradation of $\mathrm{PML}$, an effect that requires a catalytically active E6AP.

Elevated PML expression in multiple E6AP-deficient cell types. To determine whether E6AP also influences PML expression under physiological conditions, we compared the protein levels of PML between wt and E6AP-deficient cells. For this comparison, mice from both groups were killed and cell extracts were prepared from multiple organs. The protein levels of endogenous PML were measured using an antimouse PML antibody (Figure $2 \mathrm{a}$ ), which recognized multiple bands in the tissue extracts. These were considered to be $\mathrm{PML}$ proteins as they were absent from the PML-deficient mouse embryo fibroblasts (MEFs; Figure 2a lane 1 ' $C$ '). This antibody was raised against amino acids 1-581 of mouse PML, which is composed of 808 residues and is approximately $90-106 \mathrm{kDa}^{27}$ corresponding to mouse isoform 1 (NM 08884), the ortholog of the human isoform I. ${ }^{28}$ In the MEF lysates, this antibody recognized the expected $\sim 90-106 \mathrm{kDa}$ band and an additional major
$\mathrm{PML}$ isoform, at $\sim 50 \mathrm{kDa}$. Unlike the well-studied human $\mathrm{PML}$ isoforms, however, the identity of additional mouse isoforms is less clear. ${ }^{28}$ Although characterization of the mouse PML genomic structure revealed four transcripts, ${ }^{27}$ future experiments will be required to characterize the extra PML bands observed. Strikingly, the expression levels of these multiple PML bands varied between tissues and were markedly higher in E6AP KO cells derived from the kidney, prostate, lung and liver than in their normal counterparts (Figure $2 b$ ). This difference was observed in multiple mice including both males and females of different ages. A similar difference in PML expression levels was observed in the bone marrow (BM) cells derived from E6AP KO mice as compared with the wt mice (Figure $2 b$ ). We then measured PML expression in a more homogenous population of cells. For this purpose we activated $T$ cells from the spleen of wt and E6AP KO mice. Cells were fixed, stained and PML expression was compared by flow cytometry. This analysis revealed a clear increase in the mean fluorescence intensity of PML expression in the $\mathrm{T}$ blasts deficient for E6AP as compared with the wt cells (Supplementary Figure 1). Taken together, these results clearly demonstrate an elevation in PML expression in cells deficient for E6AP and underscore the function of E6AP in the regulation of PML protein levels under physiological conditions, in multiple primary cells.

E6AP regulates $P M L$ expression at the protein level. E6AP is most renown as an E3 ubiquitin ligase. However, E6AP has also been implicated in the regulation of gene transcription. ${ }^{29}$ We therefore determined at what level(s) E6AP affects PML expression. For this purpose, $\mathrm{T}$ blasts from wt or E6AP KO mice were harvested and protein levels were determined by western blot analysis, and mRNA was quantified by quantitative real-time PCR (RT-PCR). By contrast to the elevation in PML protein levels in E6AP-deficient $T$ cells (Figure $3 a$ ), there was no significant difference at the mRNA level as assessed by RT-PCR measurements (Figure $3 b$ ). This result suggests that E6AP regulates PML expression posttranscriptionally.

To determine the effect of E6AP on PML protein stability, we measured the effect of E6AP on the half-life of the PML protein. $\mathrm{H} 1299$ cells were transiently transfected with expression plasmids for PML alone or together with E6AP. The amounts and ratio of PML and E6AP expression plasmids were calibrated such that PML was clearly observed even in the presence of E6AP. At this ratio E6AP has only a mild effect on the steady-state levels of PML. $24 \mathrm{~h}$ after transfection, de novo protein synthesis was inhibited by treatment with cycloheximide for 15 or $30 \mathrm{~min}$. As shown in Figure $3 \mathrm{c}$, the half-life of the PML protein expressed in the absence of E6AP is longer than $30 \mathrm{~min}$, whereas in its presence, it shortened to be between 15 and $30 \mathrm{~min}$. Furthermore, the effect of E6AP on the half-life of PML was measured by metabolic labeling. HEK293T cells were transiently transfected with expression plasmid for PML alone, or together with wt or mutant E6AP. $48 \mathrm{~h}$ after transfection, cells were incubated with $\left[{ }^{35} \mathrm{~S}\right]$ cysteine/methionine for $1 \mathrm{~h}$ to label the newly synthesized proteins followed by a chase with normal medium for different times. The PML proteins were immunoprecipitated from the cell extracts and separated on a gel. The half-life of 


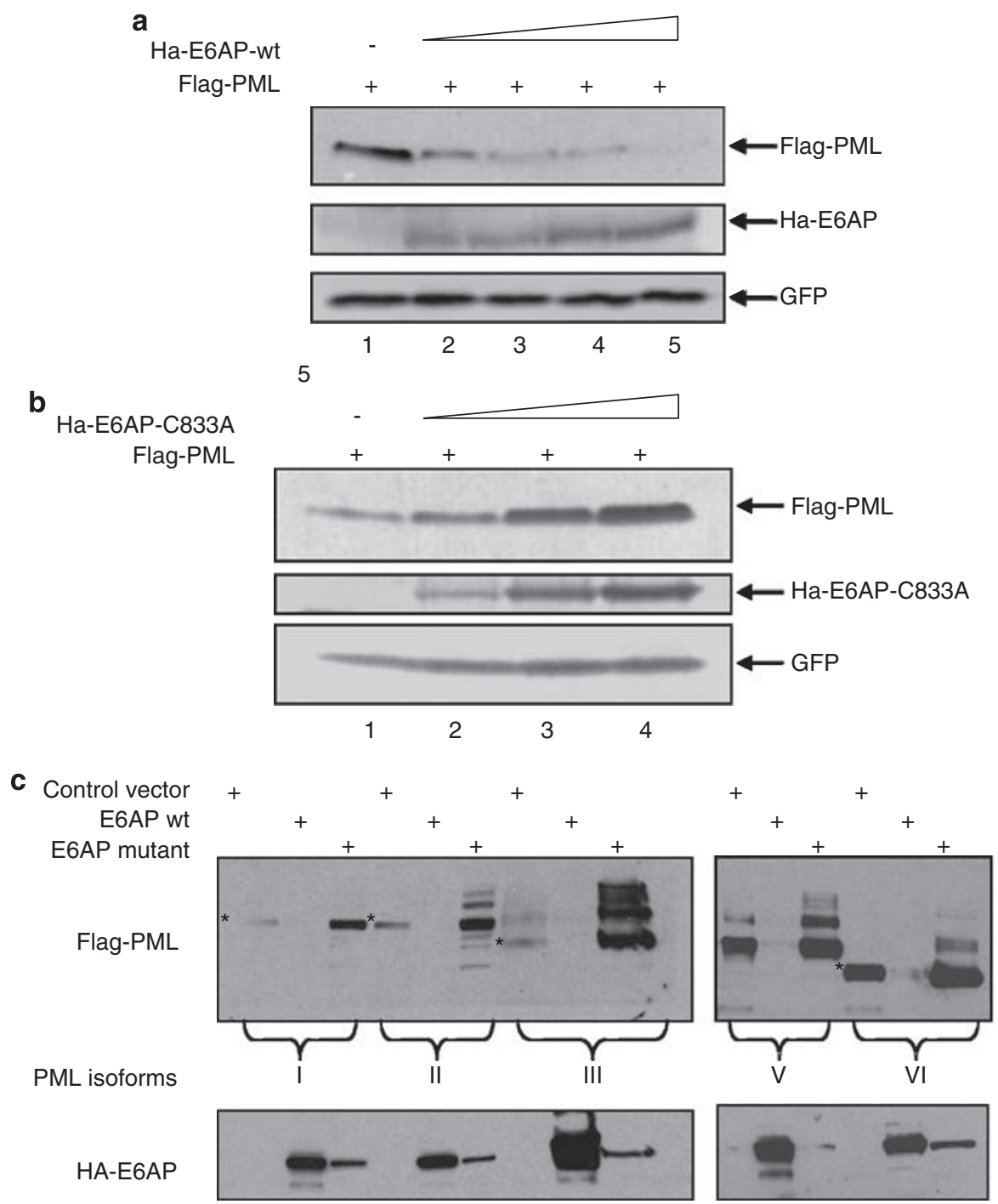

Figure 1 E6AP promotes the degradation of PML. (a) H1299 cells were transfected with expression plasmid for Flag-PML alone $(0.1 \mu \mathrm{g}$; lane 1) or together with increasing amounts of Ha-E6AP expression plasmid $(0.1 \mu \mathrm{g}$ lane 2; $0.3 \mu \mathrm{g}$ lane 3; $0.5 \mu \mathrm{g}$ lane $4 ; 1 \mu \mathrm{g}$ lane 5). At $48 \mathrm{~h}$ after transfection, cell extracts were prepared and subjected to western blot analysis, and the steady-state level of PML was determined using an anti-Flag antibody. The expression levels of E6AP were determined by reprobing the membrane with anti-Ha antibody. The transfection efficiency was monitored by transfecting constant amounts of GFP expression plasmid ( $0.25 \mu \mathrm{g})$ in each sample and measuring GFP protein levels with anti-GFP antibody. (b) H1299 cells were transfected with expression plasmids for Flag-PML alone (0.1 $\mu$ g; lane 1$)$ or cotransfected with increasing amounts of mutant Ha-E6AP-C833A expression plasmid ( $0.1 \mu \mathrm{g}$ lane 2; $0.5 \mu \mathrm{g}$ lane 3; $1 \mu \mathrm{g}$ lane 4$)$. $48 \mathrm{~h}$ after transfection, cell extracts were prepared and subjected to western blot analysis, and the steady-state levels of PML and mutant-E6AP were determined as in panel a. (c) HEK293 cells were transfected and analyzed as described in panel a with the exception that the indicated PML isoforms were used

exogenous PML was approximately $1 \mathrm{~h}$ in the presence of endogenous or exogenous E6AP. Markedly, however, the half-life of PML was longer than $4 \mathrm{~h}$ in the presence of catalytic mutant of E6AP Figure 3d. This result supports the function of E6AP in the regulation of PML stabilization. In HEK293 cells the expression of E6AP is sufficient to control PML level, including exogenous PML.

Treatment of cells with $\mathrm{As}_{2} \mathrm{O}_{3}$ has been shown to destabilize PML ${ }^{11}$ due to the effect of RNF4 on polySUMOylated $P M L,{ }^{20,21}$ we therefore measured the effect of E6AP on the degradation of PML. H1299 cells were transfected with PML together with low amounts of E6AP wt or catalytic mutant (C833A). The amount of E6AP plasmid was calibrated such that at these levels it is unable to promote
PML degradation. Under these conditions cells were either left untreated or treated with $\mathrm{As}_{2} \mathrm{O}_{3}(1 \mu \mathrm{M}$ for $2 \mathrm{~h})$. As shown in Figure $3 e$, in the presence of $\mathrm{As}_{2} \mathrm{O}_{3} \mathrm{E} 6 \mathrm{AP}$ induces the efficient degradation of PML, whereas the catalytic mutant did not. Further, we measured the effect of endogenous E6AP on the degradation of PML by $\mathrm{As}_{2} \mathrm{O}_{3}$. $\mathrm{H} 1299$ cells were transfected with PML, and $24 \mathrm{~h}$ later cells were treated with $\mathrm{As}_{2} \mathrm{O}_{3}$ and cycloheximide for selected durations. The half-life of PML in the presence of $\mathrm{As}_{2} \mathrm{O}_{3}$, but without exogenous E6AP, was between 30 and 60 min (Figure 3f). The inclusion of exogenous E6AP together with $\mathrm{As}_{2} \mathrm{O}_{3}$ markedly reduced the half-life of PML to less than 10 min (Figure $3 \mathrm{~g}$ ). To verify that the reduced half-life is E6AP-dependent, we carried out this experiment with a catalytic mutant of E6AP, C833A. 


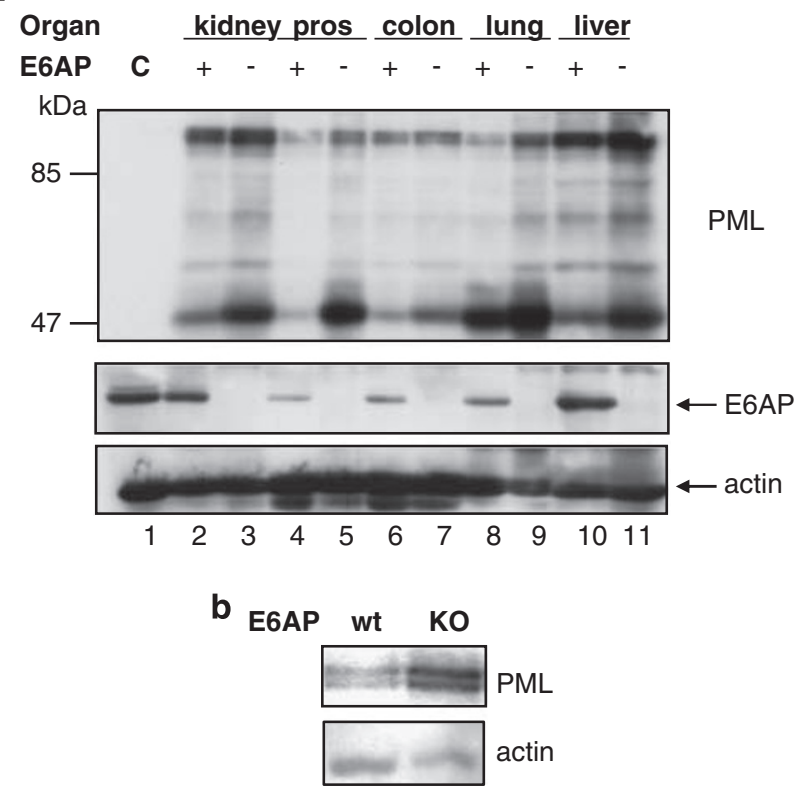

Figure 2 PML expression in E6AP KO mice is higher than in wt mice. (a) Cell extracts from the indicated organs of wt (lanes 2, 4, 6, 8, 10) or E6AP KO (lanes 3, 5, $7,9,11)$ mice were subjected to western blot analysis and the levels of the PML proteins were determined by immunoblotting with anti-mouse-PML antibody. The same blot was exposed to an anti-actin antibody to monitor loadings. The specificity of the anti-PML antibody was verified by running an extract of PML KO MEFs (lane 1, control ' $C$ '). Molecular weight markers (in $\mathrm{kDa}$ ) are indicated. (b) Extracts from freshly isolated bone marrow cells from wt or E6AP KO mice were compared for PML levels as described in panel a

Unlike the rapid degradation observed with wt E6AP, the halflife of PML in the presence of the E6AP mutant was increased to over $90 \mathrm{~min}$, which suggests that not only E6AP-C833A failed to enhance PML degradation, but in fact protected it from $\mathrm{As}_{2} \mathrm{O}_{3}$-mediated degradation (Figure $3 \mathrm{~h}$ ). To measure the effect of E6AP on the ubiquitination of PML, we transfected H1299 cells with His-tagged ubiquitin, Flag-PML in the presence or absence of exogenous E6AP. Following treatment with $\mathrm{As}_{2} \mathrm{O}_{3}$ and MG132, PML was immunoprecipitated and the extent of ubiquitination was determined by blotting with anti-His antibody. This analysis revealed a marked elevation in PML ubiquitination following $\mathrm{As}_{2} \mathrm{O}_{3}$ treatment (Supplementary Figure 2).

Because SUMOylation was essential for the degradation of PML by RNF4, ${ }^{20,21}$ we asked whether the major SUMOylation site of PML, K160, is essential for the ubiquitination of PML by E6AP. For this purpose the ubiquitination of $P M L$ and $P M L$ K160R SUMO-deficient mutant was compared. MCF-7 cells were transfected with each PML plasmid together with Histagged ubiquitin. Ubiquitinated PML was detected by a pull down of His-tagged molecules followed by blotting with antiPML (Supplementary Figure 3A). Consistent with this result PML K160R was found to be degraded by E6AP (Supplementary Figure 3C). This analysis revealed that PML K160R mutant is ubiquitinated and degraded like wt PML in an E6AP. dependent manner. Together these results demonstrate that E6AP regulates the half-life of the PML protein and that this effect requires its catalytic activity. Further, the results implicate a function for E6AP in $\mathrm{As}_{2} \mathrm{O}_{3}$-induced degradation of PML.

E6AP promotes the ubiquitination and proteasomal degradation of PML. Because E6AP is an E3 ligase, we asked whether E6AP promotes the degradation of $\mathrm{PML}$ through the ubiquitin-proteasome system. For this purpose, H1299 cells were transfected with Flag-PML alone or together with $\mathrm{Ha}-\mathrm{E} 6 \mathrm{AP}$ and $48 \mathrm{~h}$ later cells were treated with the proteasome inhibitor MG132 $(20 \mu \mathrm{M})$ for $3 \mathrm{~h}$. As shown in Figure 4a, treatment of cells with MG132 protected PML from E6AP-induced degradation. This result supports the notion that E6AP promotes the proteasomal degradation of PML. Next, we investigated whether E6AP is able to promote the ubiquitination of PML. HEK293 cells were transfected with expression plasmids for PML alone or together with increasing amounts of E6AP. To inhibit proteasomal degradation of PML by E6AP, we treated cells with MG132 for $3 \mathrm{~h}$ before harvest. The effect of E6AP on the migration of the PML protein was determined by western blot analysis using anti-Flag antibody to restrict the detection to exogenous PML only. A smear of slow migrating PML bands was enhanced in the presence of E6AP (Supplementary Figure 4A). To obtain a more direct evidence for the effect of E6AP on the ubiquitination of PML, we carried out an in vivo ubiquitination assay in MCF-7 and HEK293 cells expressing inducible shRNA to E6AP (Supplementary Figure 3C). Both cell types were transfected with PML and ubiquitin Histagged expression plasmids. Cells were treated with MG132 to inhibit the degradation of ubiquitinated PML. Ubiquitin conjugates were isolated by a pull down using nickel beads and the extent of ubiquitination of PML was defined by blotting with anti-PML antibody. As shown in Figure $4 b$, the extent of PML ubiquitination was reduced by downregulation of E6AP using shRNA. Similar results were obtained in HEK293 cells (Supplementary Figure 4B). Together these results demonstrate a function for E6AP in the ubiquitination of PML.

These findings raised the major question of whether E6AP acts as a direct E3 ligase of PML. To address this question, we measured the ability of E6AP to ubiquitinate PML in an in vitro ubiquitination assay. For a substrate ${ }^{35} \mathrm{~S}-$ Met-labeled PML was translated in a rabbit reticulocyte lysate. E6AP and $\mathrm{UbcH} 5 \mathrm{~b}$ E2 were generated in baculovirus or Escherichia coli BL21 expression systems. The extent of PML ubiquitination was determined following $2 \mathrm{~h}$ incubation under standard ubiquitination conditions. ${ }^{30}$ As shown in Figure 4c, a smear of ubiquitinated forms of PML (shown by an asterisk) and the appearance of high-molecular-weight bands was clearly visible in the combined presence of E6AP, UbcH5b and ubiquitin (lane 4), but not in their absence. The dominating bands within the smear are believed to represent multimonoubiquitinated species of PML. This result, which is reproducible in multiple experiments, strongly implicates E6AP as the direct E3 ligase of PML.

E6AP and PML interact in vivo and colocalize in the PML-NBs. The degradation of PML by E6AP raises the question of whether these two proteins physically interact 
a

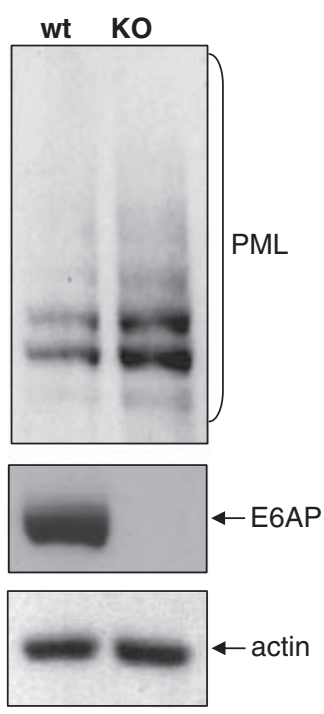

b

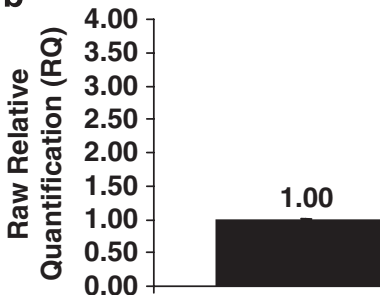

wt

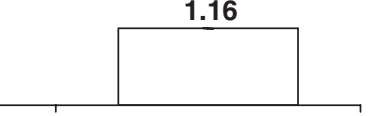

KO

C Flag-PM

Ha-E6AP

Chx(min)

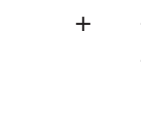

$+$
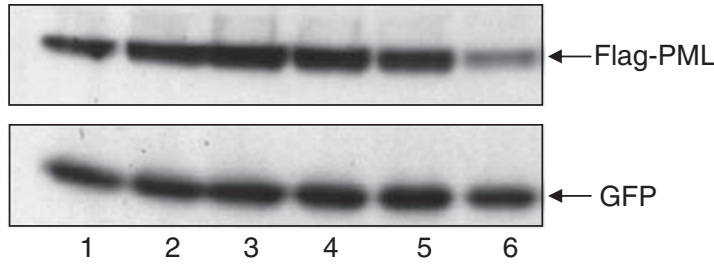

$\begin{array}{lllllll}\text { PML/GFP } & 0.54 & 0.92 & 1.24 & 0.90 & 0.60 & 0.27\end{array}$

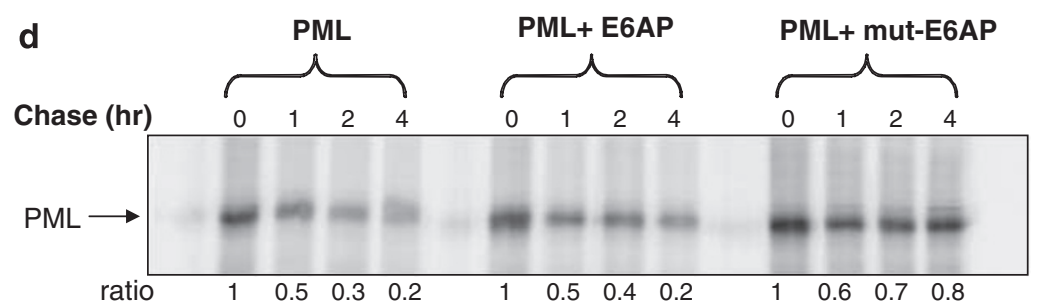

As203 - + - + - +

E6AP wt $-2++-$

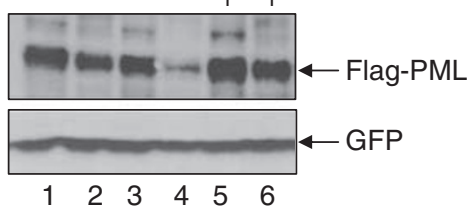

f Chx+As (min) $\quad-\quad 10 \quad 30 \quad 60 \quad 90$

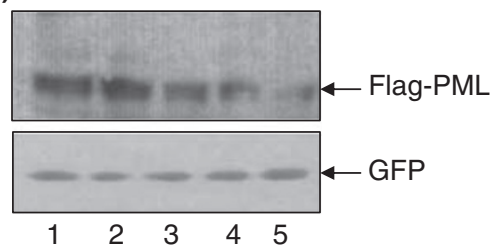

g

Ha-E6AP +++++

Chx+As (min) $\quad-\quad 10 \quad 30 \quad 60 \quad 90$

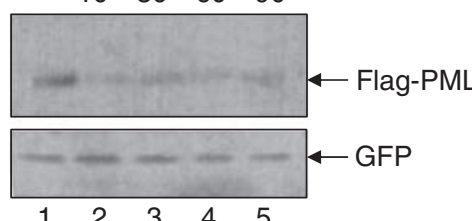

h Ha-E6AP C833A +++++

Chx+As (min)

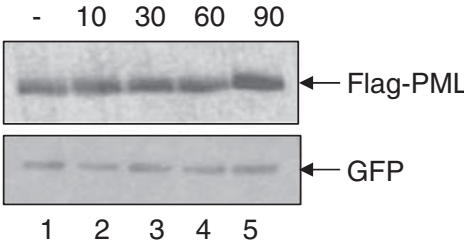

Figure 3 E6AP promotes the downregulation of PML at the protein level. (a) Activated T splenocytes from wt or E6AP KO mice were subjected to western blot analysis to measure PML protein levels and to real-time PCR analysis to measure PML mRNA levels (b). The amount of mRNA in each sample was normalized to mouse TATA box binding protein (mTBP). (c) H1299 cells were transfected with the indicated expression plasmids: Flag-PML $(1 \mu \mathrm{g})$ and wt-E6AP $(1.75 \mu \mathrm{g})$. In the indicated samples, cycloheximide (Chx; $10 \mu \mathrm{g} / \mathrm{ml})$ was added at 15 or $30 \mathrm{~min}$ before harvest, respectively. Cell extracts were subjected to western blot analysis using anti-Flag antibody, and the transfection efficiency was monitored with anti-GFP antibody. The ratio of PML/GFP band intensity was measured and presented. (d) HEK293 cells were transfected with the indicated expression plasmids and $48 \mathrm{~h}$ later metabolically labeled for $1 \mathrm{~h}$ with $\left[{ }^{35} \mathrm{~S}\right]$ cysteine/methionine and chased for the indicated time in normal medium. The PML proteins were immunoprecipitated with anti-Flag conjugated beads (Sigma), separated on SDS-PAGE and subjected to Phospholmager analysis. The ratio of the PML band intensities relative to no chase was measured and is presented below the panel. (e) H1299 cells were transfected with wt PML expression plasmid ( $1 \mu \mathrm{g}$ ) and E6AP wt or C833A mutant $(1 \mu \mathrm{g})$ and where indicated cells were treated with $\mathrm{As}_{2} \mathrm{O}_{3}(1 \mu \mathrm{M} 2 \mathrm{~h})$. Cells were then harvested and PML levels and transfection efficiencies were monitored with anti-PML (Sigma) and anti-GFP, respectively. (f) $\mathrm{H} 1299$ cells were transfected with wt PML expression plasmids and where indicated cells were treated with $\mathrm{As}_{2} \mathrm{O}_{3}(\mathrm{As} ; 1 \mu \mathrm{M})$ and $\mathrm{Chx}(10 \mu \mathrm{g} / \mathrm{ml})$ together for the indicated times. Cells were then harvested and PML levels and transfection efficiencies were monitored as described in panel $\mathbf{c}$. $\mathrm{H} 1299$ cells were transfected with expression plasmids for wt E6AP ( $1 \mu \mathrm{g} ; \mathrm{g})$, or for E6AP catalytic mutant, E6AP-C833A (1 $\mu \mathrm{g}$; $\mathbf{h})$. $24 \mathrm{~h}$ after transfection, cells were either left untreated (lane 1) or treated with $\mathrm{As}_{2} \mathrm{O}_{3}(\mathrm{As} ; 1 \mu \mathrm{M})$ and $\mathrm{Chx}(10 \mu \mathrm{g} / \mathrm{ml})$ for the indicated times. PML levels and transfection efficiencies were monitored as described in panel b 

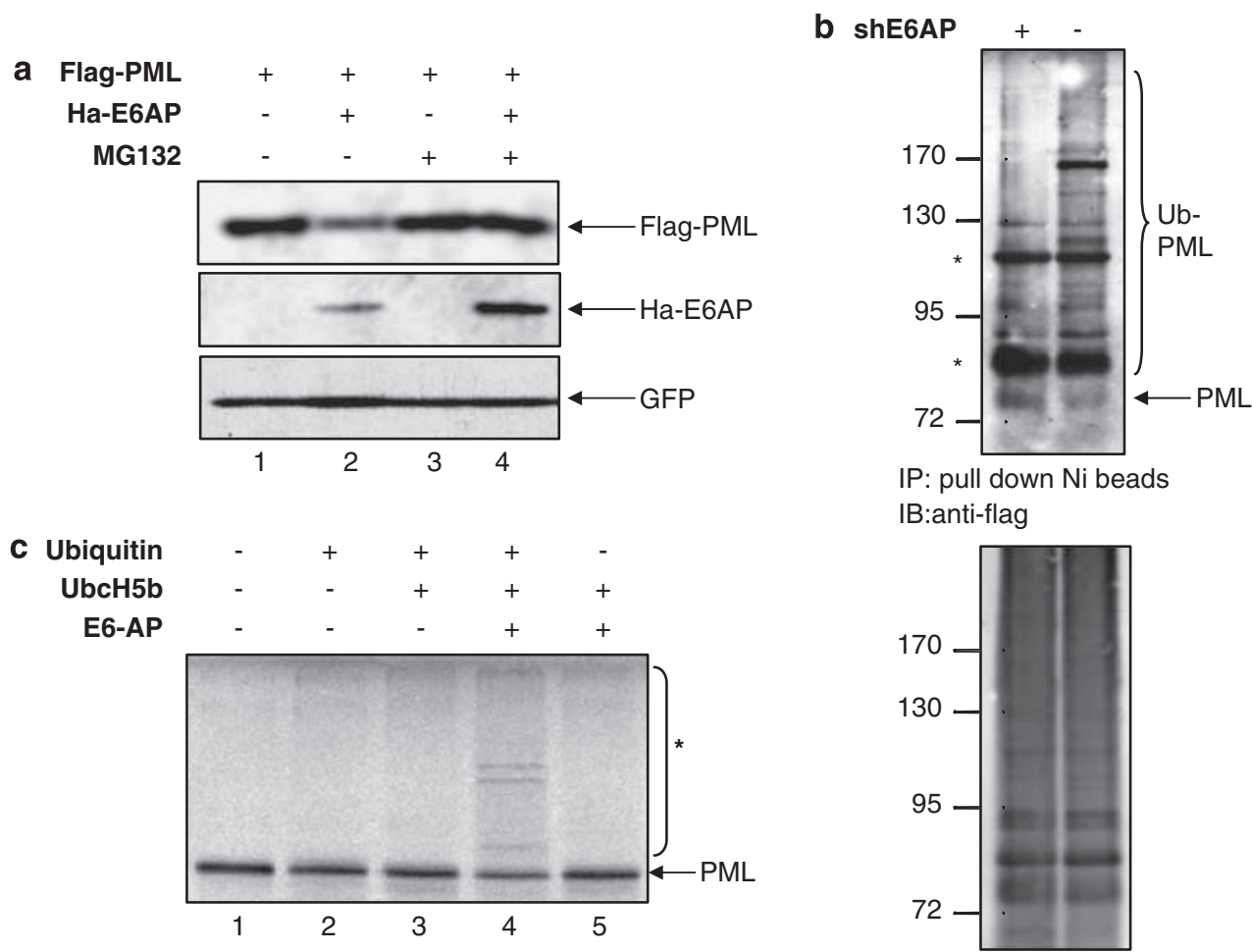

IP: pull down Ni beads IB:anti-flag

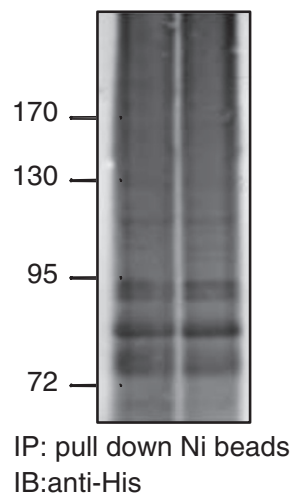

Figure 4 E6AP promotes the ubiquitination and proteasomal degradation of PML. (a) H1299 cells were transfected with the indicated expression plasmids: Flag-PML $(0.1 \mu \mathrm{g})$ alone (lanes 1,3) or together with $\mathrm{Ha}-\operatorname{E} 6 \mathrm{AP}(0.3 \mu \mathrm{g})$ (lanes 2,4). $48 \mathrm{~h}$ after transfection, cells were treated or not with MG132 $(20 \mu \mathrm{M}$ for $3 \mathrm{~h})$ before harvest and western blot analysis as in Figure 1. (b) MCF-7 cells expressing inducible shE6AP were either treated or not-treated with doxycycline for $72 \mathrm{~h}$. Cells were transfected with FlagPML $(5 \mu \mathrm{g})$ and His-tagged Ubiquitin $(10 \mu \mathrm{g})$. $24 \mathrm{~h}$ later, cells were treated with MG132 $(20 \mu \mathrm{M}, 4 \mathrm{~h})$ and lysed under denaturing conditions. Proteins linked to His-ubiquitin were purified using $\mathrm{Ni}^{2+}$-resin beads, washed and eluted with $200 \mathrm{mM}$ imidazole. His-ubiquitin PML conjugates were detected by western blotting using anti-Flag antibody (Sigma, upper panel). As control total His-ubiquitin conjugates were monitored by anti-His antibody (Sigma, lower panel). Asterisks mark nonspecific bands. (c) ${ }^{35} \mathrm{~S}-\mathrm{labeled}$ PML, translated in a rabbit reticulocyte lysate was incubated for $2 \mathrm{~h}$ under standard ubiquitination conditions in the absence or presence of ubiquitin, UbcH5b, and E6-AP. The reaction products were analyzed by SDS-PAGE followed by fluorography. Running positions of the nonmodified form (arrow) and the ubiquitinated forms (asterisk) of PML are indicated. Note that the amount of endogenous ubiquitin-activating enzyme E1 present in the rabbit reticulocyte lysate is sufficient to support E6AP-mediated ubiquitination. The results were repeated in at least three independent experiments

and colocalize within cells. To search for this interaction, we transfected HEK293 cells with expression plasmids for Flag-PML alone, or together with wt Ha-E6AP or mutant Ha-E6AP-C833A. Flag-PML was immunoprecipitated from the cell extracts using anti-Flag beads, and the presence of Ha-E6AP protein in the immune complex was determined by western blot analysis using anti-Ha antibody. An interaction between PML and both wt E6AP or E6AP-C833A mutant was clearly observed (Figure 5a). Next we examined which domain of PML interacts with E6AP. For this purpose deletion mutants of PML were subjected to the same coimmunoprecipitation assay. This analysis revealed that the coiled-coil region of PML interacts with E6AP (Figure 5b). The PML deletion mutants that interact with E6AP were also degraded by E6AP, whereas the PML RBB mutant that lacks the coiled-coil domain was refractory to E6AP effect (Supplementary Figure 5). Further, we asked whether the PML-E6AP interaction also occurs between endogenous PML and E6AP at physiological levels. E6AP was immunoprecipitated from 3T3MEFs and the amount of coprecipitated PML protein was determined. As negative controls extracts from E6AP or PML KO 3T3MEFs were used. Importantly, a specific interaction was observed between endogenous PML and E6AP in the wt MEFs (Figure 5c, lane 3), but not in the absence of PML (lane 2) or E6AP (lane 1). These results clearly demonstrate PML and E6AP interact in vivo at their physiological levels.

Given this interaction it was important to define whether E6AP affects PML-NB formation, and whether E6AP is localized in these structures. To address these questions, we co-transfected $\mathrm{H} 1299$ cells with GFP-PML and Ha-E6AP, and $24 \mathrm{~h}$ later cells were fixed and subjected to immunofluorescent staining. PML was detected by GFP fluorescence, whereas E6AP was detected with anti-Ha antibody followed by Cy5-conjugated secondary antibody. E6AP was found to localize with PML in the PML-NBs, although staining of E6AP was also found diffused within the nucleus and was clearly identified in the cytoplasm (Figure $5 \mathrm{~d}$ ). To verify that the colocalization is not due to overexpression of PML, we repeated the experiment with exogenous E6AP only, monitoring its colocalization with endogenous PML. As shown in Figure 5e, E6AP colocalized with endogenous PML in the 

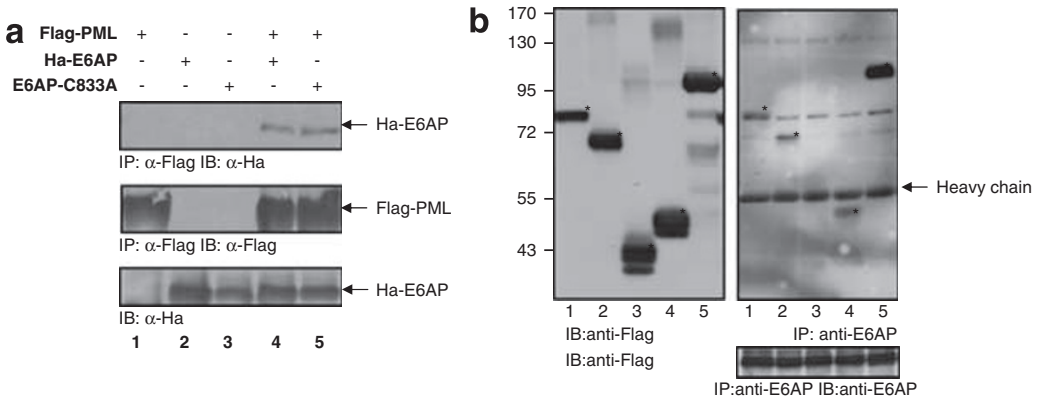

IP.anti-EGAPIB:anti-EGAP

1 PML (full length) 2 PML (deltaRINGB 3 PML (RBB) 4 PML (RBCC) 5 PML-RARalfa

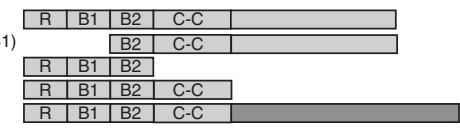

C
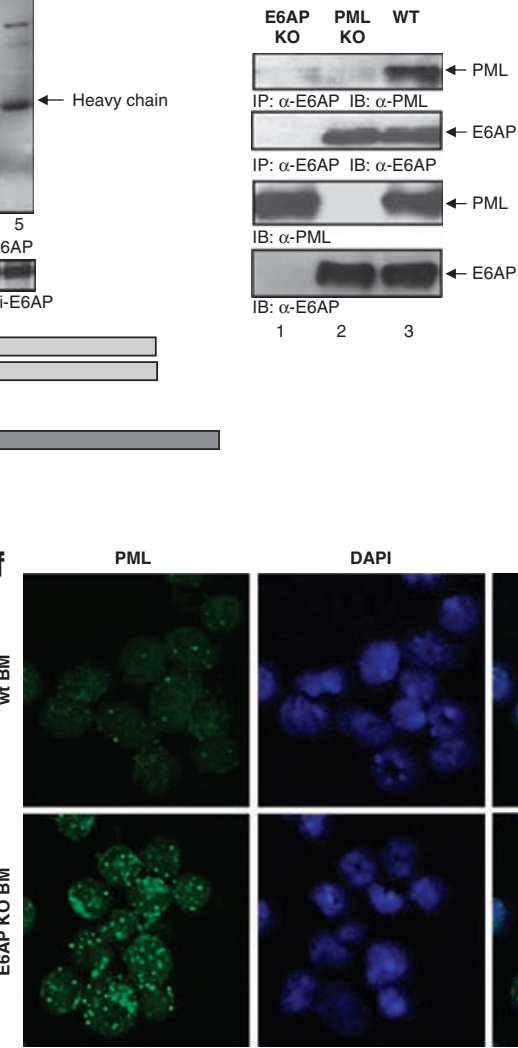

DAPI
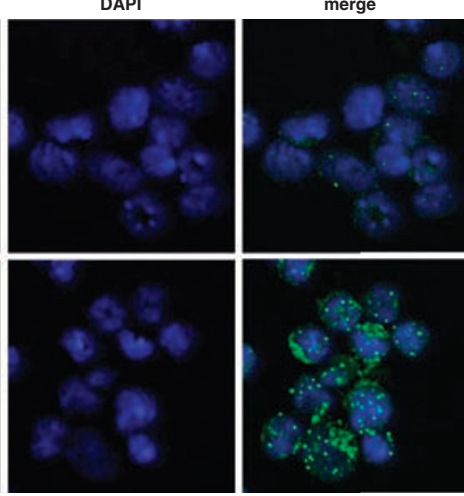

Figure 5 PML and E6AP interact and colocalize in the PML-NBs. (a) HEK293 cells were transfected with expression plasmids for Flag-PML (lane 1), Ha-E6AP (lane 2), mutant Ha-E6AP-C833A (lane 3), or PML and E6AP together (lane 4) or PML and mutant E6AP together (lane 5). At $24 \mathrm{~h}$ after transfection, cells were harvested and cell extracts were subjected to immunoprecipitation (IP) using anti-Flag antibody followed by western blot analysis (IB) using anti-Ha antibody. The expression levels of the precipitated Flag-PML were determined, and the expression levels of Ha-E6AP after transfection were determined by removing small aliquots from the cell extracts before immunoprecipitation and subjecting these to western analysis using anti-Ha antibody. (b) HEK293 cells were transfected with PML deletion mutants (left top panel). After $24 \mathrm{~h}$, E6AP was immunoprecipitated from the cell extracts using anti-E6AP antibody (Sigma). The coimmunoprecipitated PML deletion mutants (indicated by asterisks) were detected using anti-Flag antibody (Sigma, upper right panel). Schematic representation of the PML mutants is shown in the lower panel. (c) MEFs derived from E6AP KO (lane 1), PML KO (lane 2) or wt (lane 3) mice were subjected to an immunoprecipitation assay (IP) using anti-E6AP antibody followed by western blot using anti-PML antibody. The amount of E6AP in the immune complex was determined by reprobing the same membrane with anti-E6AP. The expression level of PML and E6AP in each type of MEFs before IP was determined with anti-PML or anti-E6AP antibodies, respectively. (d) H1299 cells were plated on coverslips and then transfected with expression plasmids GFPPML $(1 \mu \mathrm{g})$ and Ha-E6AP $(1 \mu \mathrm{g})$. At $24 \mathrm{~h}$ after transfection, cells were fixed and subjected to immunofluorescent staining. GFP-PML was detected by the GFP fluorescence (left panel) and the Ha-E6AP protein was detected with anti-Ha antibody, followed by Cy5-conjugated goat anti-mouse antibody (middle panel). Colocalization is shown in yellow in the merge pictures in the right panel. (e) E6AP KO MEFs were plated on coverslips and transfected with $0.5 \mu \mathrm{g} \mathrm{Ha}$-E6AP. After $24 \mathrm{~h}$, cells were treated with MG132 $(20 \mu \mathrm{M}, 4 \mathrm{~h})$, fixed and subjected to immunofluorescent staining using anti-PML polyclonal antibody (H-238; Santa Cruz) followed by Cy5-conjugated secondary antibody (green), and anti-Ha monoclonal antibody (HA.11, Covance) followed by Cy2-conjugated secondary antibody (red). Merged images are shown on the right, where colocalization is indicated in yellow (pointed by white arrows). (f) Freshly isolated bone marrow cells derived from wt or E6AP KO mice were spun onto slides. Cells were fixed and stained for PML as described in panel a with the exception of Cy2 instead of Cy5. Nuclei were detected by DNA staining using DAPI. Slides in panel $\mathbf{d}$ were visualized by Nikon fluorescent microscope ( $\times 600$ magnification) and those in panels e and $\mathrm{f}$ by Olympus confocal microscope ( $\times 600$ magnification). The results were repeated in at least three independent experiments

PML-NBs, although to a lesser extent than with exogenous PML (panel d). It should be noted that in the presence of E6AP, the number of the PML-NBs was significantly reduced, however, the size of the NBs appear to be larger and irregular in size. Next we asked whether the formation of the PML-NBs is affected by E6AP expression. BM cells freshly isolated from E6AP KO mice or wt mice were fixed and stained for PML followed by Cy3-conjugated secondary antibody. PML staining within the PML-NBs was strikingly brighter and the number of NBs was greater in the KO cells as compared with their wt counterparts where PML staining was more diffuse
(Figure 5f). These results demonstrate that E6AP colocalizes with PML in the PML-NBs and that in the absence of E6AP larger numbers of PML-NBs are formed.

E6AP-deficient lymphoid cells accumulate more PML and are more susceptible to DNA damage-induced death. DNA damage triggers the accumulation of PML and the formation of the PML-NBs. ${ }^{5}$ To examine the possibility that $E 6 A P$ regulates $P M L$ in response to genotoxic stress, we compared the extent and duration of $\mathrm{PML}$ accumulation in $\mathrm{T}$ blasts derived from wt or E6AP KO mice after exposure to 
IR (3Gy). The accumulation of PML in response to IR was higher and sustained for a longer period in the E6AP KO cells (Figure 6a, densitometric analysis in Supplementary Figure 6). Consistent with Figure 2, the basal levels of PML were also higher (twofold) in the E6AP KO cells (lanes 1 and 6). No differences were observed at the mRNA levels (data not shown), supporting the findings in Figure 3a. These results suggest that E6AP regulates the extent and duration of PML accumulation in response to DNA damage.
PML has been shown to contribute to the cellular apoptotic response to multiple stimuli. ${ }^{5}$ The effect of E6AP on the accumulation of PML and formation of NBs in response to DNA damage encouraged us to compare the function of E6AP in the cellular response to genotoxic stress. Primary $T$ blasts from wt or E6AP KO mice were subjected to IR (2-3Gy) and $22 \mathrm{~h}$ later the extent of apoptosis was determined. As shown in Figure $6 \mathrm{~b}$, E6AP $\mathrm{KO}$ cells were more susceptible to IR-induced death $(21 \%)$ relative to the wt cells (10\%). Similar
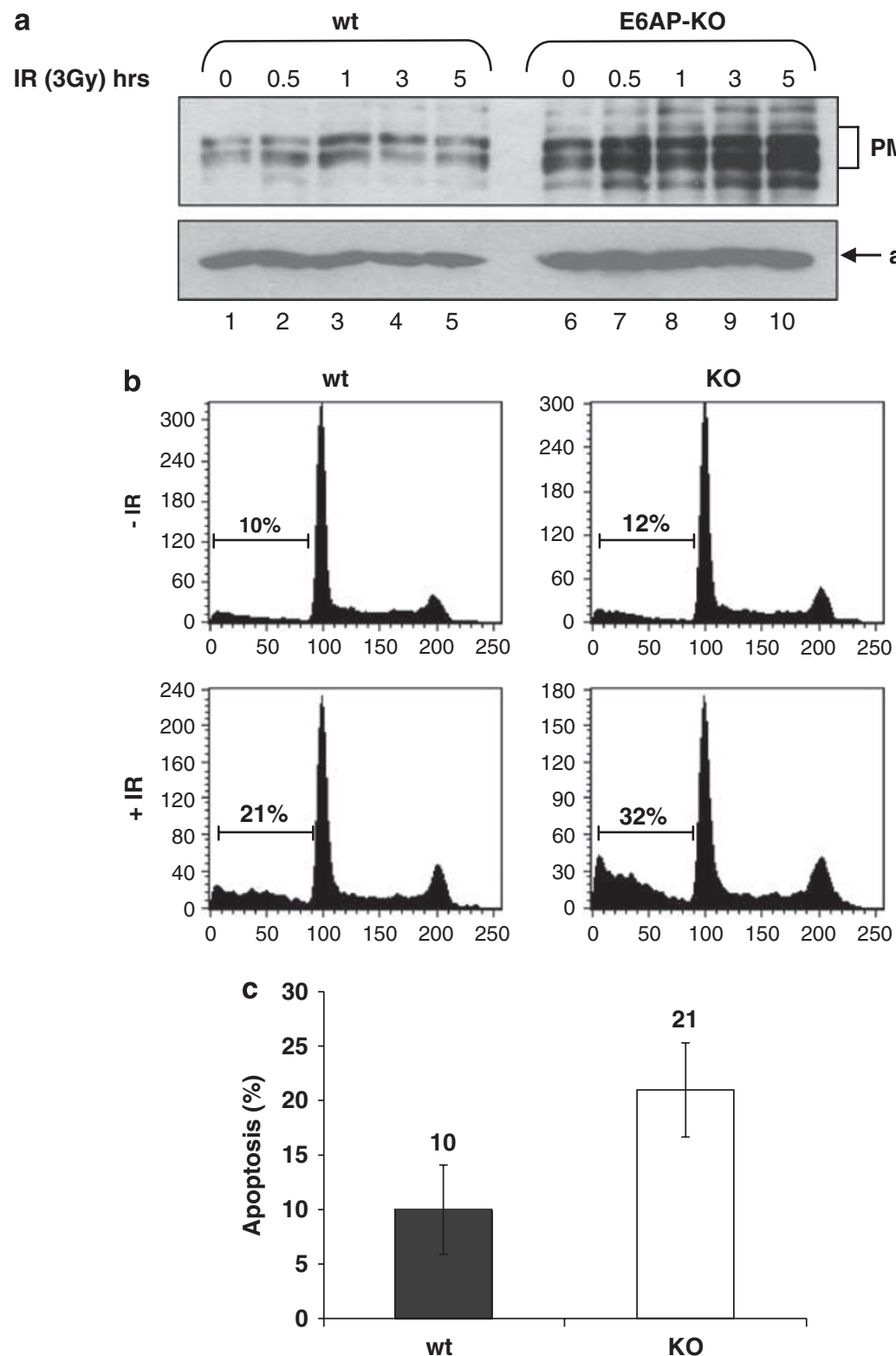

Figure 6 E6AP-deficient lymphoid cells accumulate more PML in response to DNA damage and are more susceptible to DNA damage-induced death. (a) Activated T lymphocytes derived from wt (lanes 1-5) or E6AP KO (lanes 6-10) mice were exposed to IR (3 Gy) and were harvested at the indicated times. Cell extracts were subjected to western blot analysis using anti-PML and anti-actin. The dominant PML isoforms are indicated, the lower band is assumed to be a smaller isoform, whereas the higher molecular weight bands above PML are assumed to be SUMOylated PML conjugates. (b) Activated T splenocytes derived from wt or E6AP KO mice were exposed to IR (3 Gy) and $18 \mathrm{~h}$ later cells were harvested, fixed and the proportion of cell death was measured by flow cytometry. DNA content was measured by propidium iodide (PI) staining, and the proportion of cells with sub-G $\mathrm{G}_{1}$ DNA content was determined. A summary of the results is shown in panel $\mathbf{c}$. At least three independent experiments were carried out with similar results 
results were observed with BM-derived B cells (data not shown). These results support a function for E6AP in the apoptotic response of lymphoid cells to genotoxic stress.

\section{Discussion}

A function for PML and PML-NBs in the regulation of cellular stress responses has been well established. PML acts upstream of multiple stress signaling pathways, regulating DNA repair, cell-cycle arrest, cell survival and cell death (reviewed in references ${ }^{1,8,9}$ ). In this study, we explored a new pathway in the regulation of PML and the PML-NBs. Our results show that E6AP dictates PML protein levels. This led us to investigate the nature of the contribution of E6AP to this process and we provide several lines of evidence to support the notion that E6AP is an E3 ligase of PML. First, E6AP promotes the proteasomal degradation of multiple isoforms of PML (Figures 1 and 4). Second, E6AP shortens the half-life of the PML protein (Figure 3). Third, a catalytic mutant of E6AP, C833A, failed to induce PML degradation (Figure 1) or to shorten the half-life of PML (Figure 3). Intriguingly, this mutant actually stabilizes PML, presumably by acting as a dominant negative over endogenous E6AP (Figures 1 and 3). Fourth, E6AP promotes the ubiquitination of $\mathrm{PML}$ in vivo and in vitro (Figures 3 and 4, Supplementary Figures 2-4). These data implicate a direct function for E6AP in the regulation of PML proteasomal degradation. This direct link is supported by the physical interaction between endogenous PML and E6AP in vivo at physiological levels, and by colocalization of exogenously expressed proteins in the PML-NBs under stress conditions (Figures 5 and 6). The regulation of PML by E6AP is demonstrated by the elevated basal levels of $P M L$ proteins in multiple tissues and primary cells derived from E6APdeficient mice (Figure 2). E6AP controls the expression of multiple human (Figure 1) and mouse (Figure 2) PML isoforms. Within the human protein, the coiled-coil region of $\mathrm{PML}$ is required for its interaction with and degradation by E6AP (Figure 5, Supplementary Figure 5).

Consistent with the effect of E6AP on PML protein levels, we observed increased numbers and intensity of PML-NBs in hematopoietic cells lacking E6AP (Figure 6). The PML-NBs in the MEFs from E6AP KO mice are functional, judged by the normal recruitment of PML and Daxx to the PML-NBs following DNA damage (data not shown). In response to stress, PML undergoes posttranslational modifications. $\mathrm{As}_{2} \mathrm{O}_{3}$ treatment induces the accumulation of SUMOylated PML and leads to its subsequent proteasomal degradation. ${ }^{11}$ Recent findings have demonstrated that the degradation of arsenic-induced poly-SUMOylated PML is mediated by the SNURF. 20,21 Our results suggest that E6AP may also contribute to the degradation of $\mathrm{PML}$ in response to $\mathrm{As}_{2} \mathrm{O}_{3}$ treatment (Figure 3). Future studies would define whether E6AP and RNF4 cooperate in the degradation of PML. Previously, Scaglioni et al. ${ }^{13}$ demonstrated a function for CK2mediated phosphorylation of PML on S517 in the control of PML stability. It will be pertinent to examine a possible link between CK2- and E6AP-mediated degradation.

The association between E6AP and cancer was demonstrated in HPV-infected cells, where it overcomes growth inhibition by targeting p53 for degradation. ${ }^{23,24}$ We and others have shown that PML protects p53 from Mdm2-mediated degradation. ${ }^{31-33}$ Our finding that E6AP promotes PML degradation defines a new molecular link between E6AP and p53 in the absence of HPV infection. Indeed, elevated p53 levels were previously reported in postmitotic neurons of a maternally deficient E6AP mouse, ${ }^{22}$ in neuronal cells after partial knockdown of $\mathrm{EAP}^{34}$ and in prostate cells from E6AP $\mathrm{KO}$ mice. ${ }^{35}$ In addition to HPV-dependent cancers, elevation in E6AP expression was found in mouse mammary tumors, ${ }^{36}$ whereas downregulation of E6AP was observed in breast and prostate carcinomas. ${ }^{37}$ The latter is associated with increased levels of steroid receptors, which are established targets of E6AP.

Deregulation of PML can contribute to malignancies. In addition to the $t(15 ; 17)$ chromosomal translocation in patients with APL, a partial or complete loss of PML has been observed in multiple human cancers, including colon and prostate adenocarcinomas. ${ }^{4}$ The implication of PML as a tumor suppressor is strongly supported by mouse models. ${ }^{1,6}$ Importantly, the loss of PML expression is at the protein level rather than at the mRNA level. Further, in solid tumors and invasive epithelial tumors, PML protein levels are decreased in a proteasomal-dependent manner. ${ }^{4}$ This loss of PML expression has been associated with tumor progression ${ }^{4}$ and has been shown to correlate with elevated CK2 kinase activity. ${ }^{13}$ Our results predict a correlation between elevated E6AP expression and a loss of PML expression in the same tumor types. Future experiments will test this hypothesis.

\section{Materials and Methods}

Plasmids. Wt Flag-PML-IV was kindly provided by PP Pandolfi (Memorial SloanKettering, NY, USA). Human wt PML-IV was formally referred to as PCDNA3PML3. Ha-wt-E6AP (pCDNA3E6AP) and Ha-mutant C833A-E6AP (pCDNA3 C833A-E6AP) were kind gifts from Z Nawaz (Baylor College Houston, TX, USA). pEGFP-N1 encoding GFP was purchased from Clontech Laboratories Inc (Mountain View, CA, USA).

Antibodies and reagents. Monoclonal antibodies against actin (clone AC-40), human PML (clone PML-97), E6AP (clone E6AP-330), polyhistidine (clone HIS-1), Flag (M2) and Flag conjugated to agarose beads were obtained from Sigma (St. Louis, MO, USA). Monoclonal antibodies to the hemagglutinin motif 'HA' HA.11 were obtained from Covance (Berkeley, CA, USA). Monoclonal antibodies to mouse PML (clone 36.1-104) were procured from Upstate Biotechnology Inc. (Lake Placid, NY, USA). Anti-GFP was purchased from Roche Applied Science (Basel, Switzerland); anti-ubiquitin antibody from Zymed Laboratories. The secondary antibodies goat anti-mouse HRP and their FITC, Cy2, Cy3 and Cy5 conjugates were from Jackson ImmunoResearch Laboratories Inc. (West Grove, PA, USA). The proteasome inhibitor MG132 was from Calbiochem (San Diego, CA, USA). All other reagents were from Sigma unless otherwise indicated.

Cell culture. HEK293 cells were grown at $37^{\circ} \mathrm{C}$ in Dulbecco's modified Eagle's medium (DMEM), and H1299 lung adenocarcinoma cells were grown in RPMI medium supplemented with $10 \%$ fetal calf serum. MEFs were prepared from Ube3A $\mathrm{KO}$ embryos or wt embryos at day 13.5 according to standard protocol. MEFs lacking PML were obtained from PP Pandolfi. ${ }^{38}$ All MEFs were grown in DMEM with $10 \%$ heat-inactivated fetal calf serum and supplements.

Pulse-chase analysis. HEK293T cells were incubated in cysteine/ methionine-free media (Gibco) for $45 \mathrm{~min}$ followed by incubation with media containing $150 \mu \mathrm{Ci}^{35} \mathrm{~S}$-labeled cysteine/methionine (PerkinElmer) for $1 \mathrm{~h}$. Cells were then washed and incubated in complete DMEM for $0,1,2$ and $4 \mathrm{~h}$. The PML proteins were immunoprecipitated with anti-Flag antibody and then separated on $8 \%$ SDS-PAGE and subjected to Phospholmager analysis. ${ }^{35} \mathrm{~S}$-signal was quantified using ImageQuant software. 
Mice. Ube3A wt and $\mathrm{KO}$ mice ${ }^{39}$ were maintained on $\mathrm{C} 57 \mathrm{BL} / 6$ background under SPF restriction. Mice were genotyped as previously described. ${ }^{22}$

Transfection, immunoprecipitation and immunoblotting. Transfections were carried out as previously described. ${ }^{40}$ The amounts of expression plasmids used are indicated in the corresponding figure legends. Western blot analysis and immunoprecipitation assays were carried out essentially as previously described. Tissues were homogenized and sonicated on ice in lysis buffer before electrophoresis.

\section{Ubiquitination assay}

In vitro assay. E6-AP and UbcH5b were expressed in the baculovirus system or in E. coli BL21 as previously described..$^{30}$ For in vitro ubiquitylation $2 \mu$ l of ${ }^{35}$ S-labeled $\mathrm{PML}$, translated in a rabbit reticulocyte lysate, was incubated with $50 \mathrm{ng}$ of $\mathrm{UbcH} 5 \mathrm{~b}$ and $20 \mu \mathrm{g}$ of ubiquitin in the absence or in the presence of $200 \mathrm{ng}$ of E6AP in $40 \mu$ reaction volume. In addition, reactions contained $25 \mathrm{mM}$ Tris- $\mathrm{HCl}(\mathrm{pH}$ 7.5), $5 \mathrm{mM}$ $\mathrm{NaCl}, 1 \mathrm{mM}$ dithiothreitol, $2 \mathrm{mM} \mathrm{ATP}$ and $4 \mathrm{mM} \mathrm{MgCl}_{2}$. After incubation at $30^{\circ} \mathrm{C}$ for $2 \mathrm{~h}$, total reaction mixtures were electrophoresed in a $10 \%$ SDS-PAGE, and the ${ }^{35}$ S-labeled PML was detected by fluorography. As controls, reactions lacking ubiquitin, E6AP, UbcH5b or all three were included.

In vivo assay. Cell were transfected with Flag-PML and $\mathrm{His}_{6}$-tagged ubiquitin plasmids. After $24 \mathrm{~h}$ cells were treated with MG132 $(20 \mu \mathrm{M}, 4 \mathrm{~h})$ before harvest. Lysis was performed in $6 \mathrm{M}$ guanidinium- $\mathrm{HCl}, 0.1 \mathrm{M} \mathrm{Na} 2 \mathrm{HPO}_{4} / \mathrm{NaH}_{2} \mathrm{PO}_{4}, 0.01 \mathrm{M}$ Tris- $\mathrm{HCl}(\mathrm{pH} 8.0), 20 \mathrm{mM}$ imidazole and $10 \mathrm{mM} \beta$-mercaptoethanol. Extract was incubated with $\mathrm{Ni}^{2+}$-ProBond Resin beads (Invitrogen) overnight at $4^{\circ} \mathrm{C}$. Beads were successively washed ( 5 min per wash) with $1 \mathrm{ml}$ of the following buffers: $6 \mathrm{M}$ guanidinium- $\mathrm{HCl}, 0.1 \mathrm{M} \mathrm{Na} 2 \mathrm{HPO}_{4} / \mathrm{NaH}_{2} \mathrm{PO}_{4}, 0.01 \mathrm{M}$ Tris- $\mathrm{HCl}(\mathrm{pH} 8.0)$, plus $0.2 \%$ Triton $\mathrm{X}$-100 and $10 \mathrm{mM} \beta$-mercaptoethanol; $8 \mathrm{M}$ urea, $0.1 \mathrm{M} \mathrm{Na}_{2} \mathrm{HPO}_{4} / \mathrm{NaH}_{2} \mathrm{PO}_{4}$ $0.01 \mathrm{M}$ Tris- $\mathrm{HCl}(\mathrm{pH} 8.0), 0.2 \%$ Triton $\mathrm{X}-100$ and $10 \mathrm{mM} \beta$-mercaptoethanol; $8 \mathrm{M}$ urea, $0.1 \mathrm{M} \mathrm{Na} \mathrm{HPO}_{4} / \mathrm{NaH}_{2} \mathrm{PO}_{4}, \quad 0.01 \mathrm{M}$ Tris- $\mathrm{HCl}$ (pH 6.3), $10 \mathrm{mM}$ $\beta$-mercaptoethanol (buffer A) plus $0.2 \%$ Triton X-100; and then buffer A plus $0.1 \%$

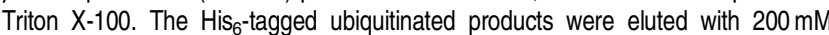
imidazole, $0.15 \mathrm{M}$ Tris- $\mathrm{HCl}$ (pH 6.7), 20\% glycerol, $0.72 \mathrm{M} \beta$-mercaptoethanol, $5 \%$ SDS for $20 \mathrm{~min}$ at room temperature and analysed by western blotting.

Immunofluorescent staining. Activated mouse T splenocytes were fixed in methanol $\left(-20^{\circ} \mathrm{C}\right)$ and stained for PML and detected with FITC-conjugated goat anti-mouse secondary antibody. The fluorescence intensity of PML stained T cells was monitored and analyzed by a cell sorter (FACSCalibur) using CellQuest software (BD Biosciences). For microscopic examination cells were fixed (either with ice-cold methanol for $\mathrm{H} 1299$ or with $4 \%$ paraformaldehyde for $15 \mathrm{~min}$, then permeabilized with $0.1 \%$ Triton $X$ for 5 min for 3T3MEFs and mouse BM cells) then stained for PML and detected by Cy2- or Cy3-conjugated goat anti-mouse secondary antibodies. DNA was stained with DAPI (4',6'-diamidino-2-phenylindole). Cells were visualized by two fluorescent microscopes as indicated in the figure legend for each image. The first is the Nikon PlanApo, and images were captured with SensiCam CCD camera and processed by Image Proplus version 4.5.1.2. The second is Olympus FV1000 confocal laser microscope, and images were processed with Fluoview1000 V.1.5 software. Images were viewed at $\times 600$ magnification under oil immersion with objective NA 1.35 at room temperature.

Real-time PCR assay. Cellular RNA was isolated by Tri-Reagent (MRC Inc. Cincinnati, $\mathrm{OH}, \mathrm{USA}$ ) using the manufacturer's instructions. DNA was removed from the samples using DNAse treatment (DNA-free kit; Applied Biosystems, Foster City, CA, USA). cDNA was synthesized from the purified RNA using M-MLV reverse transcription kit (Promega, Madison, WI, USA). Mouse-PML primers used for RT-PCR were designed with ABI PRISM Primer Express software (Applied Biosystems). The sequences of the mouse PML primers are as follows: PML forward primer $\left(5^{\prime}\right.$-cctgcgctgactgacatctact- $\left.3^{\prime}\right)$ and PML reverse primer $\left(5^{\prime}\right.$-tgcaacacagaggcttggc- $\left.3^{\prime}\right)$. The sequences of the MTBP primers are as follows: mTBP forward primer $\left(5^{\prime}\right.$-ggcctctcagaagcatcacta- $\left.3^{\prime}\right)$ and mTBP reverse primer $\left(5^{\prime}\right.$-gccaagccctgagcataa-3'). RT-PCR was performed using SYBR-Green PCR Master Mix (Applied Biosystems). Samples were amplified in ABI PRISM 7500 Real-Time detection system (Applied Biosystems) under the following conditions: $50^{\circ} \mathrm{C}$ for $2 \mathrm{~min}, 95^{\circ} \mathrm{C}$ for $10 \mathrm{~min}$, followed by 40 cycles of $95^{\circ} \mathrm{C}$ for $15 \mathrm{~s}, 60^{\circ} \mathrm{C}$ for $1 \mathrm{~min}$. Gene expression was quantified using the relative $\mathrm{Ct}$ method of the 7500 system SDS software (Applied Biosystems).

For downregulation of E6AP the following shRNA sequences of E6AP were used: forward primer CGCGTCCCCgaagcagttgtatgtggaaTTCAAGAGAttccacata
caactgcttcTTTTTGGAAAT and reverse primer CGATTTCCAAAAAgaagcagttg tatgtggaaTCTCTTGAAttccacatacaactgcttcGGGGA. These sequences were introduced into pLVTHM lentiviral vector (kindly provided by D Trono). Infected cells were treated with $0.2 \mu \mathrm{g} / \mathrm{ml}$ doxycycline for $72 \mathrm{~h}$.

Acknowledgements. We thank Z Nawaz, A Ben-Zeev, D Trono, L Banks and PP Pandolfi for their generous gifts of expression plasmids; A Beaudet for the EGAP KO mice; and PP Pandolfi for the PML KO MEFs. This work was supported by grants from the Association for International Cancer Research, the German-Israeli Foundation for Scientific Research and Development, the Israel Science Foundation (grant no. 1341/05), the Australian National Health and Medical Research Council to YH (no. 509196), and by the Active p53 project within the 6th framework program of the European Commission (contract 503576). The content of this publication reflects the author's views. European Commission is not liable for any that may be made of this information.

1. Bernardi R, Pandolfi PP. Structure, dynamics and functions of promyelocytic leukaemia nuclear bodies. Nat Rev Mol Cell Biol 2007; 8: 1006-1016.

2. de The H, Lavau C, Marchio A, Chomienne C, Degos L, Dejean A. The PML-RAR alpha fusion mRNA generated by the $t(15 ; 17)$ translocation in acute promyelocytic leukemia encodes a functionally altered RAR. Cell 1991; 66: 675-684.

3. Kakizuka A, Miller Jr WH, Umesono K, Warrell Jr RP, Frankel SR, Murty VV et al. Chromosomal translocation $t(15 ; 17)$ in human acute promyelocytic leukemia fuses RAR alpha with a novel putative transcription factor, PML. Cell 1991; 66: 663-674.

4. Gurrieri C, Capodieci P, Bernardi R, Scaglioni PP, Nafa K, Rush LJ et al. Loss of the tumor suppressor PML in human cancers of multiple histologic origins. J Natl Cancer Inst 2004; 96: $269-279$

5. Bernardi R, Pandolfi PP. Role of PML and the PML-nuclear body in the control of programmed cell death. Oncogene 2003; 22: 9048-9057.

6. Trotman LC, Alimonti A, Scaglioni PP, Koutcher JA, Cordon-Cardo C, Pandolfi PP. Identification of a tumour suppressor network opposing nuclear Akt function. Nature 2006; 441: 523-527.

7. Maul GG, Negorev D, Bell P, Ishov AM. Review: properties and assembly mechanisms of ND10, PML bodies, or PODs. J Struct Biol 2000; 129: 278-287.

8. Dellaire G, Bazett-Jones DP. PML nuclear bodies: dynamic sensors of DNA damage and cellular stress. Bioessays 2004; 26: 963-977.

9. Takahashi Y, Lallemand-Breitenbach V, Zhu J, de The H. PML nuclear bodies and apoptosis. Oncogene 2004; 23: 2819-2824

10. Everett RD, Rechter S, Papior P, Tavalai N, Stamminger T, Orr A. PML contributes to a cellular mechanism of repression of herpes simplex virus type 1 infection that is inactivated by ICPO. J Virol 2006; 80: 7995-8005.

11. Lallemand-Breitenbach V, Zhu J, Puvion F, Koken M, Honore N, Doubeikovsky A et al. Role of promyelocytic leukemia (PML) sumolation in nuclear body formation, $11 \mathrm{~S}$ proteasome recruitment, and As2O3-induced PML or PML/retinoic acid receptor alpha degradation. J Exp Med 2001; 193: 1361-1371.

12. Fanelli M, Fantozzi A, De Luca P, Caprodossi S, Matsuzawa S, Lazar MA et al. The coiledcoil domain is the structural determinant for mammalian homologues of Drosophila Sinamediated degradation of promyelocytic leukemia protein and other tripartite motif proteins by the proteasome. J Biol Chem 2004; 279: 5374-5379.

13. Scaglioni PP, Yung TM, Cai LF, Erdjument-Bromage $H$, Kaufman AJ, Singh B et al. A CK2-dependent mechanism for degradation of the PML tumor suppressor. Cell 2006; 126: 269-283.

14. Kamitani T, Kito K, Nguyen HP, Wada H, Fukuda-Kamitani T, Yeh ET. Identification of three major sentrinization sites in PML. J Biol Chem 1998; 273: 26675-26682.

15. Muller S, Dejean A. Viral immediate-early proteins abrogate the modification by SUMO-1 of PML and Sp100 proteins, correlating with nuclear body disruption. J Virol 1999; 73: $5137-5143$

16. Nacerddine K, Lehembre F, Bhaumik M, Artus J, Cohen-Tannoudji M, Babinet $\mathrm{C}$ et al. The SUMO pathway is essential for nuclear integrity and chromosome segregation in mice. Dev Cell 2005; 9: 769-779.

17. Gong L, Millas S, Maul GG, Yeh ET. Differential regulation of sentrinized proteins by a novel sentrin-specific protease. J Biol Chem 2000; 275: 3355-3359.

18. Shen TH, Lin HK, Scaglioni PP, Yung TM, Pandolfi PP. The mechanisms of PML-nuclear body formation. Mol Cell 2006; 24: 331-339.

19. Zhu J, Gianni M, Kopf E, Honore N, Chelbi-Alix M, Koken M et al. Retinoic acid induces proteasome-dependent degradation of retinoic acid receptor alpha (RARalpha) and oncogenic RARalpha fusion proteins. Proc Natl Acad Sci USA 1999; 96: 14807-14812.

20. Tatham MH, Geoffroy MC, Shen L, Plechanovova A, Hattersley N, Jaffray EG et al. RNF4 is a poly-SUMO-specific E3 ubiquitin ligase required for arsenic-induced PML degradation. Nat Cell Biol 2008; 10: 538-546.

21. Lallemand-Breitenbach V, Jeanne M, Benhenda S, Nasr R, Lei M, Peres $L$ et al. Arsenic degrades PML or PML-RARalpha through a SUMO-triggered RNF4/ubiquitin-mediated pathway. Nat Cell Biol 2008; 10: 547-555. 
22. Jiang $\mathrm{YH}$, Armstrong $\mathrm{D}$, Albrecht $\mathrm{U}$, Atkins $\mathrm{CM}$, Noebels $\mathrm{JL}$, Eichele $\mathrm{G}$ et al. Mutation of the Angelman ubiquitin ligase in mice causes increased cytoplasmic p53 and deficits of contextual learning and long-term potentiation. Neuron 1998; 21: 799-811.

23. Scheffner M, Huibregtse JM, Vierstra RD, Howley PM. The HPV-16 E6 and E6-AP complex functions as a ubiquitin-protein ligase in the ubiquitination of p53. Cell 1993; 75: 495-505.

24. Talis AL, Huibregtse JM, Howley PM. The role of E6AP in the regulation of p53 protein levels in human papillomavirus (HPV)-positive and HPV-negative cells. J Biol Chem 1998; 273: 6439-6445.

25. Huibregtse JM, Scheffner M, Howley PM. A cellular protein mediates association of $\mathrm{p} 53$ with the E6 oncoprotein of human papillomavirus types 16 or 18. EMBO J 1991; 10: 4129-4135.

26. Guccione E, Lethbridge KJ, Killick N, Leppard KN, Banks L. HPV E6 proteins interact with specific PML isoforms and allow distinctions to be made between different POD structures. Oncogene 2004; 23: 4662-4672.

27. Goddard AD, Yuan JQ, Fairbairn L, Dexter M, Borrow J, Kozak $C$ et al. Cloning of the murine homolog of the leukemia-associated PML gene. Mamm Genome 1995; 6: 732-737.

28. Condemine W, Takahashi Y, Zhu J, Puvion-Dutilleul F, Guegan S, Janin A et al. Characterization of endogenous human promyelocytic leukemia isoforms. Cancer Res 2006; 66: 6192-6198.

29. Dhananjayan SC, Ismail A, Nawaz Z. Ubiquitin and control of transcription. Essays Biochem 2005; 41: 69-80.

30. Nuber U, Schwarz S, Kaiser P, Schneider R, Scheffner M. Cloning of human ubiquitinconjugating enzymes $\mathrm{UbcH} 6$ and $\mathrm{UbcH} 7(\mathrm{E} 2-\mathrm{F} 1)$ and characterization of their interaction with E6-AP and RSP5. J Biol Chem 1996; 271: 2795-2800.

31. Louria-Hayon I, Grossman T, Sionov RV, Alsheich O, Pandolfi PP, Haupt Y. The promyelocytic leukemia protein protects p53 from Mdm2-mediated inhibition and degradation. J Biol Chem 2003; 278: 33134-33141.
32. Bernardi R, Scaglioni PP, Bergmann S, Horn HF, Vousden KH, Pandolfi PP. PML regulates p53 stability by sequestering Mdm2 to the nucleolus. Nat Cell Biol 2004 6: 665-672.

33. Kurki S, Latonen L, Laiho M. Cellular stress and DNA damage invoke temporally distinct Mdm2, p53 and PML complexes and damage-specific nuclear relocalization. J Cell Sc 2003; 116 (Part 19): 3917-3925.

34. Mishra A, Jana NR. Regulation of turnover of tumor suppressor p53 and cell growth by E6-AP, a ubiquitin protein ligase mutated in Angelman mental retardation syndrome. Cell Mol Life Sci 2008; 65: 656-666.

35. Khan OY, Fu G, Ismail A, Srinivasan S, Cao X, Tu Y et al. Multifunction steroid receptor coactivator, E6-associated protein, is involved in development of the prostate gland. Mol Endocrinol 2006; 20: 544-559.

36. Sivaraman L, Nawaz Z, Medina D, Conneely OM, O'Malley BW. The dual function steroid receptor coactivator/ubiquitin protein-ligase integrator E6-AP is overexpressed in mouse mammary tumorigenesis. Breast Cancer Res Treat 2000; 62: 185-195.

37. Gao X, Mohsin SK, Gatalica Z, Fu G, Sharma P, Nawaz Z. Decreased expression of e6-associated protein in breast and prostate carcinomas. Endocrinology 2005; 146 1707-1712.

38. Guo A, Salomoni P, Luo J, Shih A, Zhong S, Gu W et al. The function of PML in p53dependent apoptosis. Nat Cell Biol 2000; 2: 730-736.

39. Tsai TF, Jiang YH, Bressler J, Armstrong D, Beaudet AL. Paternal deletion from Snrpn to Ube3a in the mouse causes hypotonia, growth retardation and partial lethality and provides evidence for a gene contributing to Prader-Willi syndrome. Hum Mol Genet 1999; 8: $1357-1364$.

40. Berger M, Stahl N, Del Sal G, Haupt Y. Mutations in proline 82 of $p 53$ impair its activation by Pin1 and Chk2 in response to DNA damage. Mol Cell Biol 2005; 25: 5380-5388.

\section{Supplementary Information accompanies the paper on Cell Death and Differentiation website (http://www.nature.com/cdd)}

